DOI 10.37882/2223-2982.2021.04-2.06

\title{
СРАВНИТЕЛЬНО-СОПОСТАВИТЕЛЬНЫЙ АНАЛИЗ КАТЕГОРИЙ РОДА И ЧИСЛА СУЩЕСТВИТЕЛЬНЫХ ВО ФРАНЦУЗСКОМ И ИТАЛЬЯНСКОМ ЯЗЫКАХ В АСПЕКТЕ ИХ ВЛИЯНИЯ НА АДЕКВАТНОСТЬ ПЕРЕВОДА
}

\section{COMPARATIVE ANALYSIS OF CATEGORIES OF GENDER AND NUMBER IN THE FRENCH AND ITALIAN LANGUAGES IN TERMS OF THEIR INFLUENCE ON TRANSLATION ADEQUACY}

N. Epifantseva

I. Likhodkina

Summary: The article is devoted to the comparison of the category of gender and number of nouns in French and Italian. Comparative analysis allows to identify differences in the implementation of these categories that affect the adequacy of translation. Theoretical statements are supported by factual material - texts from French works of fiction of the XX-XXI centuries and their translations into Italian. In conclusion, it is said that the divergence of grammatical gender can cause either minor deformations or a complete distortion of meaning and images. At the same time, cases of violation of the adequacy of translation due to differences in the category of number of compared languages were not revealed.

Keywords: category of gender, category of number, French language, Italian language, translation, adequacy of translation.

\section{Обшая характеристика работы}

$\mathrm{C}$ равнительно-сопоставительный подход к изучению различных языковых явлений доказал свою состоятельность, а методы сравнения и сопоставления широко используются лингвистами для выявления сходств и различий исследуемых языков, служащих базой в процессе перевода.

Известно, что сходства языков облегчают процесс перевода, в то время как языковые различия могут стать существенным препятствием к достижению адекватности перевода. Французский и итальянский языки, в рамках индоевропейской семьи, принадлежат к одной романской группе, галло-романской (французский) и итало-романской подгруппам, восходящим через народную латынь к одному праязыку - латинскому. Структурно оба рассматриваемых языка относятся к одному типу - аналитическому, однако черты аналитизма в них проявляются в разной степени: они более выражены во
Епифанцева Наталия Глебовна

д.филол.н., профессор, Московский государственный областной университет nepifantseva@yandex.ru

Лиходкина Ирина Александровна д.филол.н., дочент, Военный университет Министерства обороны Российской Федерации, г. Москва irina.lihodkina@gmail.com

Аннотация: Статья посвящена сопоставлению категории рода и числа существительных во французском и итальянском языках. Сравнительно-сопоставительный анализ позволяет выявить различия в реализации данных категорий, оказывающие влияние на адекватность перевода. Теоретические положения подкреплены фактическим материалом - текстами из французских художественных произведений XX-XXI вB. и их переводов на итальянский язык. В заключении делается вывод о том, что дивергенция категории рода может вызвать как незначительные деформации, так и полное искажение смысла и образов. В то же время случаи нарушения адекватности перевода из-за различий категории числа сопоставляемых языков обнаружены не были.

Ключевые слова: категория рода, категория числа, французский язык, итальянский язык, перевод, адекватность перевода.

французском языке и менее - в итальянском. Данный факт не может не сказаться на адекватности перевода, выполняемого между этой языковой парой.

Фактическим материалом исследования служат французские художественные прозаические произведения XX-XXI вв. и их переводы на итальянский язык.

Анализ трудов по теме исследования продемонстрировал их незначительное количество и недостаточность изучения объекта. Как правило, основное, и часто единственное, внимание уделено описанию грамматических аспектов рассматриваемых в статье языков. Научные и учебные отечественные и зарубежные издания по теоретической и практической грамматикам французского и итальянского языков важны, однако дают представление лишь об одной конкретной языковой структуре. Немногочисленные работы по сравнительной типологии романских языков, среди которых особого упоминания заслуживают работы Т.А. Репиной [4] и М.М. Петрунина 
[3; 11], посвященные их конвергенции и дивергенции, не затрагивают вопросы перевода.

Изложенное выше свидетельствует об актуальности данного исследования, цель которого заключается в выявлении различий в категориях рода и числа имен существительных французского и итальянского языков, влияющих на степень адекватности перевода.

\section{Сопоставление категорий рода франчузских и ита^ьянских сушествительных в аспекте перево $\Delta$}

Категория рода имен существительных свойственна обоим сопоставляемым языкам и представлена двумя формами - мужской и женской. Следует различать понятия грамматического или формального рода и естественного рода или пола. Совпадение этих двух понятий наблюдается лишь у одушевленных субъектов - антропонимов, например, mari/femme (фр.), marito/moglie (итал.), муж/жена (рус.) и частично зоонимов, например, chat/ chatte (фр.), gatto/gatta (итал.), кот/кошка (рус.), однако проявляется оно нерегулярно и не может рассматриваться как устойчивое правило, поскольку род - категория грамматическая, а пол - биологическая [14, р. 110].

Во французском и итальянском языках категория рода, превалируя над полом, играет значимую роль и часто приводит к амбилогии при понимании тех или иных лексических единиц, взятых вне контекста, и в процессе перевода может сопровождаться определенными трудностями. Например, словосочетание son journal / il suo giornale может означать в обоих языках его или её газета в зависимости от пола обладателя данного предмета.

Перевод, выполняемый на уровне предложения, далеко не всегда позволяет определить «обладателя». Так происходит со следующими фразами: Sa vie: à peine quelques ronds dans l'eau [7, p. 84] / La sua vita: appena qualche cerchio nell'acqua [8, p. 73] и Sa tête tombe et se relève sans cesse [7, p. 128] / La sua testa cade e si rialza senza interruzione [8, p. 113]. Словосочетания sa vie / la sua vita и sa tête / la sua testa могут быть в равной степени поняты как его или ее жизнь и его или ее голова. При переводе между исследуемой парой языков такая двусмысленность сохраняется, т.к. притяжательное местоимение согласуется в роде и числе с идущим за ним существительным. Таким образом, читатели исходного и переводного текстов находятся в равных условиях и сами интерпретируют подобные выражения.

Род существительных в итальянском языке, как правило, легко определим по окончанию, тогда как во французском языке принадлежность к мужскому или женскому роду может быть определена лишь в ряде случаев.

Среди прочих показателей рода во французском языке служат:

1. суффиксы, например, -ment, -eur: département, porteur (департамент, носитель) как показатели мужского рода и -ance, -tion: action, surveillance (акция, наблюдение) и их варианты как показатели женского рода;

2. окончание "e", указывающее на принадлежность к женскому роду: étudiant/étudiante (студент/ студентка). При изучении французского языка род ряда имен существительных рекомендуется запоминать: la perle, le casque, une amphore, le squelette, la haine, le caprice, la carpe, la nouille, le cigare, la proiela garde, le violoncelle и мн. др. [2].

По итогам сравнительного анализа категории рода французского и итальянского языков в историческом аспекте, У.С. Брайн [6] были выявлены основные случаи несовпадения рода в рассматриваемых языках:

1. существительные с суффиксом -оrе в итальянском языке, не обозначающие производителя какоголибо действия или профессию и сохранившие мужской род латинского языка, и французские существительные женского рода с суффиксом -eur, например: ит. il fiore / фр. la fleur (цветок), il colore / la couleur (цвет), il calore / la chaleur (жара);

2. ряд итальянских слов мужского рода имеют латинское происхождение, которые в свою очередь произошли из греческого языка, в то время как эти же слова пришли во французский непосредственно из греческого и относятся к женскому роду: ит. l'orologio / фр. I'horloge (часы), il metodo / la méthode (метод), l'inchiostro / l'encre (чернила);

3. большинство слов среднего рода латинского языка стали женского рода во французском языке и мужского - в итальянском: фр. la mer / ит. il mare (море), la paire / il paio (пара), la seconde / il secondo (секунда) [6, р. 17-18];

4. ряд девербативов женского рода во французском языке в итальянском языке относятся к мужскому роду: фр. la nage / ит. il nuoto (плавание), la suite / il seguito (следование), l'arrivée / l'arrivo (прибытие);

5. многие существительные третьего склонения классической латыни стали женского рода во французском языке и мужского - в итальянском: фр. la dent / ит. il dente (зуб), la limite / il limite (лимит).

Дивергенция категории рода может сказаться на адекватности перевода. Показателен пример перевода философской повести-сказки французского писателя Антуана де Сент-Экзюпери "Le Petit Prince" [13], 1943 г. («Маленький принц») на итальянский язык (“II Piccolo Principe") [12].

Написанное в форме детской сказки данное произведение затрагивает важные темы: дружба и любовь, одиночество и утрата, смысл жизни и природа челове- 
ка. Образы персонажей играют первостепенную роль, и их интерпретация влияет на понимание всего текста. Так, опрос итальянцев показал, что персонаж лиса ("Іе renard") воспринимается как женский, что во многом объясняется несовпадением рода у существительных, обозначающих данное животное: "le renard" -слово мужского рода во французском языке и "la volpe" - женского рода в итальянском языке. То же самое происходит и с рядом других оригинальных образов, таких как"le mouton" (м.р.), "la fleur" (ж.р.) имеющих противоположный род в переводящем языке: “la pecora” (ж.р.), “il fiore” (м.р.).

Для наглядности сравним несколько отрывков оригинала и его перевода.

- Je suis un renard, dit le renard [13, p. 63]. / "Sono una volpe", disse la volpe [12, p. 56].

- Je ne puis pas jouer avec toi, dit le renard. Je ne suis pas apprivoisé [13, p. 63]. / "Non posso giocare con te", disse la volpe," non sono addomestica" [12, p. 97].

II n'aura jamais pu l'attacher au mouton. Alors je me demande: "Que s'est-il passé sur sa planète? Peut-être bien que le mouton a mangé la fleur..." [13, p. 89] / Non avrà mai potuto mettere la museruola alla pecora. Allora mi domando: "Che cosa sarà successo sul suo pianeta? Forse la pecora ha mangiato il fiore..." [12, p. 131].

Можно заметить, что в данных фрагментах категория рода выражена аналитически, с помощью детерминативов (неопределенным, определенным или слитным артиклями), а также при согласовании причастия с подлежащим. Поскольку у персонажей нет имен, переводчик, а за ним и читатель, стараются правильно интерпретировать образы, созданные автором. Также примечателен факт наличия в итальянском языке слова мужского рода "il montone", которое эквивалентно французскому - "le mouton".

Интересно отметить, что при переводе "Le Petit Prince" на русский язык также возникли споры о способах разрешения переводческих сложностей, вызванных дивергенцией рода. Н. Галь писала, что в редакции произошла дискуссия о том, какую лексическую единицу следует употребить Лис или Лиса. Некоторые видели в этом персонаже соперницу Розе. Однако Н. Галь убедила, что Лис - образ дружбы, а Роза - любви, они не соперничают и дополняют друг друга [1, с. 330].

Тем не менее пример трудностей, возникших при переводах известного произведения А. де Сент-Экзюпери, скорее является исключением, чем закономерностью, поскольку несовпадение рода лексики исходного и переводящего языков редко приводит к значительным смысловым или стилистическим ошибкам.
В своем романе "Et si c'était vrai..." [9] М. Леви специально употребляет существительное женского рода "une mule" (самка мула) во фразе elle est têtue comme une mule [9, p. 119], вместо более привычных "un mulet" и "un âne", т.к. речь идет о девушке. Использование эквивалентной идиомы в итальянском переводе [10], содержащей слово мужского рода, - è testarda come un mulo [10, p. 110] - сохраняет смысл и образность оригинала, а контекст уточняет пол героини.

В народных и литературных сказках главными героями нередко выступают животные, растения, мифические существа, наделяемые человеческими качествами. Так, среди названий сборника сказок М. Эме "Les contes du chat perché" [5] («Сказки кота Мурлыки») встречаем следующие: Les vaches; Le chien; Les bœufs; Le paon; Le loup; Le cerf et le chien; L'éléphant; Le canard et la panthère; Le mauvais jars; L'âne et le cheval; Le mouton; Les cygnes; Le petit coq noir; La buse et le cochon. Образы представленных животных могут быть интерпретированы в зависимости от грамматического рода обозначающих их лексических единиц и описания их характеристик писателем. Задача переводчика - верно передать замысел автора, с учетом факта возможного несовпадения грамматического и естественного родов персонажей.

\section{Сопоставление категорий числа франчузских и} ита^ьянских сушествительных в аспекте перево $\Delta$

Другой не менее важной грамматической категорией имени существительного считается категория числа, основанная на отношениях количества и представленная двумя формами: единственным и множественным числом. Несмотря на принадлежность французского и итальянского языков к аналитическому типу, формирование множественного числа в них осуществляется поразному. В большинстве случаев во французском языке множественное число существительного образуется от единственного путем прибавления окончания -s, которое не отражается в произношении. Данная особенность компенсируется в устной речи детерминативами или таким фонетическим явлением, как связывание. В итальянском же языке происходит замена одного окончания другим: а/о на е или i, е на і в зависимости от рода. Таким образом, число оказывается заключенным в орфографии самого существительного.

Проиллюстрируем данные утверждения на примере французских фраз и их переводов на итальянский язык:

Louis propose qu'Armand soit chargé d'établir un descriptif sommaire du lieu sur la base des éléments dont on dispose [7, p. 117]. / Louis propone che Armand metta giù una descrizione del lungo sulla base degli elementi disponibili $[8$, p. 103]. 
Quand la conversation retombe, on écoute les nouvelles, les chansons [7, p. 275]. / Quando la conversazione langue ascoltano le notizie, le canzoni [8, p. 237].

Можно заметить, что в итальянском варианте число всех 7 существительных, представленных в предложениях, маркировано их собственной формой, а также подкреплено артиклями и рядом прилагательных. Во французских фразах, напротив, число существительных возможно определить только при помощи дополнительных средств, в данном случае - артиклей. Тем не менее нередко категория числа не выражена фонетически, как, например, в выделенном курсивом словосочетании: Cette fille, telle qu'il l'imagine, marchait sur le trottoir, faisait signe au chauffeur de bus [7, p. 57] / La ragazza, così come la immagina mentre cammina sul marciapiede, mentre fa segno all'autista dell'autobus [8, p. 50]. Данный факт способен вызвать ряд сложностей при устном французскоитальянском переводе: замедление ритма выполнения перевода, паузы из-за ожидания контекста, способствующего преодолению двусмысленности. Подобные трудности не возникают при письменном переводе.

Существуют немногочисленные расхождения имен существительных в сопоставляемых языках по форме числа. Например, слово "I'argent" (деньги) во французском языке единственного числа, а в итальянском "i soldi” множественного: Ils ont laisse de l'argent pour le café [7, p. 57] / Le hanno lasciato dei soldi per il caffè [8, p. 50]. Слово "les gens" (люди), напротив, множественного числа во французском языке, a "la gente" - единственного числа в итальянском: Ici, les gens se connaissent, comme dans un village [9, p. 14]. / Da queste parti la gente si conosce come fosse in un paese [10, p. 15].

\section{Заключение}

Проведенный сравнительно-сопоставительный анализ грамматических категорий рода и числа французского и итальянского языков позволил выявить как сходства, так и различия в их реализации и сделать ряд существенных для теории перевода выводов.

Несмотря на принадлежность сопоставляемых язы- ков к одной языковой группе - романской и к одному структурному типу - аналитическому, формирование категорий рода и числа в них имеет больше различий, чем сходств.

Если в итальянском языке род имен существительных в большинстве случаев возможно определить по их окончанию, то во французском языке принадлежность существительного к мужскому или женскому роду далеко не всегда очевидна и требует запоминания.

Преобладание грамматического рода над естественным (т.е. полом) нередко приводит к амбилогии при французско-итальянском переводе, непреодолимой даже с учетом широкого контекста. Тем не менее в подобных ситуациях переводчик и читатели оригинального и переводного текстов оказываются в равных условиях и способны самостоятельно интерпретировать авторскую мысль.

Были отмечены случаи искажения образов героев из-за дивергенции категории рода. Так, например, образ Лиса из «Маленького принца» А. де Сент-Экзюпери воспринимается как мужской ("le renard”) в оригинале, и как женский ("la volpe") - в итальянском переводе.

Категория числа в итальянском языке, как правило, маркирована формой самого существительного, тогда как во французском языке она фонетически определима только посредством дополнительных элементов - детерминативов или связывания. Данный факт может вызвать незначительные сложности при выполнении устного перевода, однако никогда не приводит к нарушению адекватности при переводе письменном.

Итак, различия в категории рода французского и итальянского языков могут привести к переводческим трудностям и вызвать нарушение адекватности межъязыкового перевода: от незначительных деформаций до полного искажения смысла и образов. В отличие от категории рода, дивергенция категории числа сопоставляемых языков практически никогда не сказывается на адекватности перевода.

\section{ЛИТЕРАТУРА}

1. Галь Н. Слово живое и мертвое. - М.: Время, 2007. - 592 с.

2. Епифанцева Н.Г., Корж В.И. Французская морфология: имя и глагол. - М.: МГПУ, 2006. - 128 с.

3. Петрунин М.М. Сравнительный анализ имени существительного в языках романской группы // Вестник Тамбовского университета. Серия: Филологические науки и культурология. - Тамбов: ТГУ им. Г.Р. Державина, 2015. № 3 (3). - С. 50-56.

4. Репина Т.А. Сравнительная типология романских языков (французский, итальянский, испанский, португальский, румынский). - СПб.: Изд-во С.Петербургского ун-та, 1996. $-280 \mathrm{c}$.

5. Aymé M. Les contes du chat perché. - Paris: Gallimard, 2017. - $416 \mathrm{p}$. 
6. Bryan W.S. Comparison of Gender in French and Italian: A Historical Perspective / Senior Thesis Projects, 1993-2002 [Electronic resource]. Access mode: http://trace. tennessee.edu/utk_interstp2/60

7. Lemaitre P. Alex. - Paris: Le Livre de Poche, 2012. - 408 p.

8. Lemaitre P. Alex / Trad. di S. Viviani. - Milano: Mondadori, 2011. - 342p.

9. Levy M. Et si c'était vrai... - Paris: Robert Laffont, 2014. - 254 p.

10. Levy M. Se solo fosse vero / Trad. di B. Pagni Frette. - Bergamo: BUR,

11. Petrunin M. Comparative Grammar of Italian and French: Learn \& Compare 2 Languages Simultaneously. Independently published by M. Petrunin, 2019. - 502 p.

12. Saint-Exupéry A. de II Piccolo Principe / Trad. di N. Bompiani Bregoli. - Milano: Bompiani, 2014. - 133 p.

13. Saint-Exupéry A. de Le Petit Prince. - M.: Jupiter-Inter, 2003. - 92 p.

14. Vinay J.-P., Darbelnet J. Stylistique comparée du français et de l'anglais. - Paris: Didier Scolaire, 2004. - 331 p.

○ Епифанцева Наталия Глебовна (nepifantseva@yandex.ru), Лиходкина Ирина Александровна (irina.lihodkina@gmail.com).

Журнал «Современная наука: актуальные проблемы теории и практики»

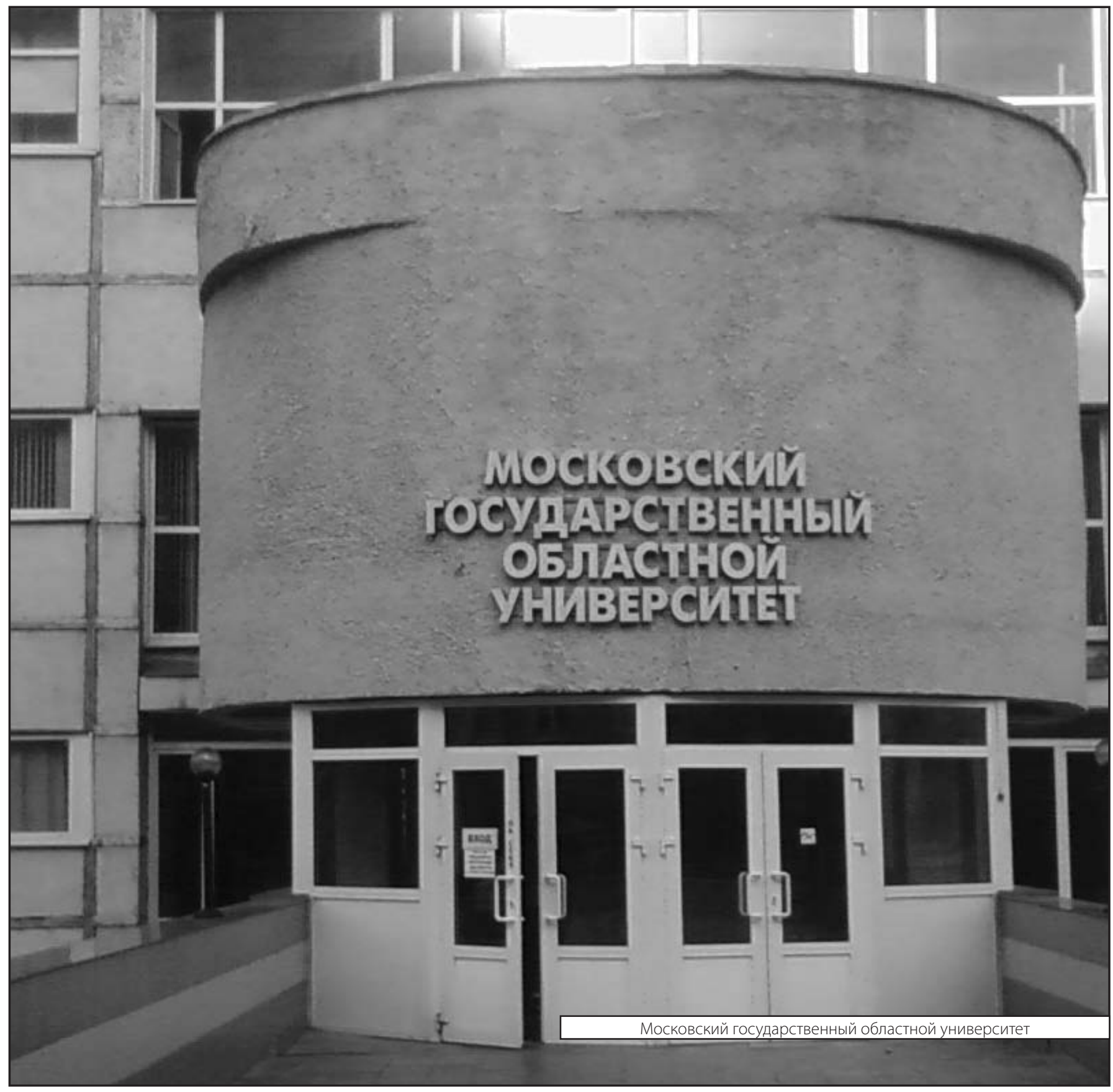

